\title{
Production of Diabetic Offspring Using Cryopreserved Epididymal Sperm by In Vitro Fertilization and Intrafallopian Insemination Techniques in Transgenic Pigs
}

\author{
Kazuhiro UMEYAMA ${ }^{1,2)}$, Kasumi HONDA ${ }^{1)}$, Hitomi MATSUNARI',2), Kazuaki NAKANO ${ }^{1)}$, \\ Tatsuro HIDAKA ${ }^{1)}$, Keito SEKIGUCHI ${ }^{1}$, , Hironori MOCHIZUKI ${ }^{1}$, Yasuhiro TAKEUCHI ${ }^{1}$, \\ Tsukasa FUJIWARA ${ }^{1)}$, Masahito WATANABE ${ }^{1,2)}$, Masaki NAGAYA ${ }^{2)}$ and Hiroshi NAGASHIMA ${ }^{1,2)}$ \\ 1) Laboratory of Developmental Engineering, Department of Life Sciences, School of Agriculture, Meiji University, \\ Kanagawa 214-8571, Japan \\ 2) Meiji University International Institute for Bio-Resource Research, Kanagawa 214-8571, Japan
}

\begin{abstract}
Somatic cell nuclear transfer (SCNT) is a useful technique for creating pig strains that model human diseases. However, production of numerous cloned disease model pigs by SCNT for large-scale experiments is impractical due to its complexity and inefficiency. In the present study, we aimed to establish an efficient procedure for proliferating the diabetes model pig carrying the mutant human hepatocyte nuclear factor- $1 \alpha$ gene. A founder diabetes transgenic cloned pig was generated by SCNT and treated with insulin to allow for normal growth to maturity, at which point epididymal sperm could be collected for cryopreservation. In vitro fertilization and intrafallopian insemination using the cryopreserved epididymal sperm resulted in diabetes model transgenic offspring. These results suggest that artificial reproductive technology using cryopreserved epididymal sperm could be a practical option for proliferation of genetically modified disease model pigs.
\end{abstract}

Key words: Cryopreserved epididymal sperm, Diabetes model pigs, Intrafallopian insemination, In vitro fertilization,

Transgenic offspring

(J. Reprod. Dev. 59: 599-603, 2013)

T he physiology and anatomy of pigs closely resemble those of humans; for this reason, pigs are regarded as a large animal model that can produce experimental data that are easily extrapolated to humans [1]. In recent years, genetic modification techniques have been used to develop pig strains that model several human diseases [2, 3].

We created genetically modified (GM) pigs that exhibit the symptoms of diabetes similar to maturity onset diabetes of the young 3 (MODY3). The diabetic symptoms of the GM pigs were induced by the dominant-negative effect of a transgene, human mutant hepatocyte nuclear factor 1 alpha (HNF-1 $\alpha)$ [4]. In applying GM pigs to translational research, it must be ensured that enough animals can be supplied for experiments. Therefore, we aimed to establish an efficient procedure for proliferating our diabetes model pig by means of artificial reproductive technologies. In this study, the founder transgenic (Tg) cloned pig was generated by somatic cell nuclear transfer (SCNT) and treated with insulin to allow for normal growth to maturity, at which point epididymal sperm could be collected for cryopreservation.

Here, we report that in vitro fertilization (IVF) and intrafallopian insemination using cryopreserved epididymal sperm are useful options for reproducing the diabetes model pig. This reproductive system

Received: June 12, 2013

Accepted: July 15, 2013

Published online in J-STAGE: August 24, 2013

(C)2013 by the Society for Reproduction and Development

Correspondence: H Nagashima (e-mail: hnagas@isc.meiji.ac.jp) can theoretically be applied to other GM pigs, thereby enhancing the utility of disease model GM pigs.

Porcine fetal fibroblast cells carrying mutant human HNF-1 $\alpha$ [4] were used to generate the founder Tg pigs by SCNT. SCNT was performed as described elsewhere using in vitro matured (IVM) oocytes as recipient cytoplasts [5]. In total, $333 \mathrm{SCNT}$ embryos were generated and transferred to three estrus-synchronized gilts on day 1 or day 2; each recipient received 116, 109 or 108 embryos. The gilt that had received 116 embryos became pregnant and farrowed four Tg-cloned pigs. Three of the four piglets died within two days of birth for unidentified reasons or from being crushed by the recipient sow. The surviving piglet developed hyperglycemia (non-fasting blood glucose level: $374 \mathrm{mg} / \mathrm{dl}$ ) at two weeks of age.

Administration of insulin started at three weeks of age, and the pig was raised for 15 months as the founder Tg-cloned boar. The non-fasting blood glucose level of the founder Tg-cloned boar was maintained at approximately $200 \mathrm{mg} / \mathrm{dl}$ by administration of a combination of regular insulin (Novolin R, Novo Nordisk, Bagsvaerd, Denmark) and long-acting insulin glargine (Lantus, Sanofi, Paris, France) (Table 1). The target blood glucose level was set higher than the normal blood glucose level for pigs $(85-150 \mathrm{mg} / \mathrm{dl})$ to avoid the risk of hypoglycemic coma.

The level of 1,5-anhydroglucitol (1,5-AG) in the founder Tg-cloned boar was lower than that in healthy pigs (Table 1), indicating that the animal developed hyperglycemia. By contrast, the levels of blood urea nitrogen (BUN) and of triglyceride (TG) in the blood during the insulin administration period were similar to those of healthy 
Table 1. Biochemical parameters in the plasma of the diabetes model founder transgenic-cloned pig

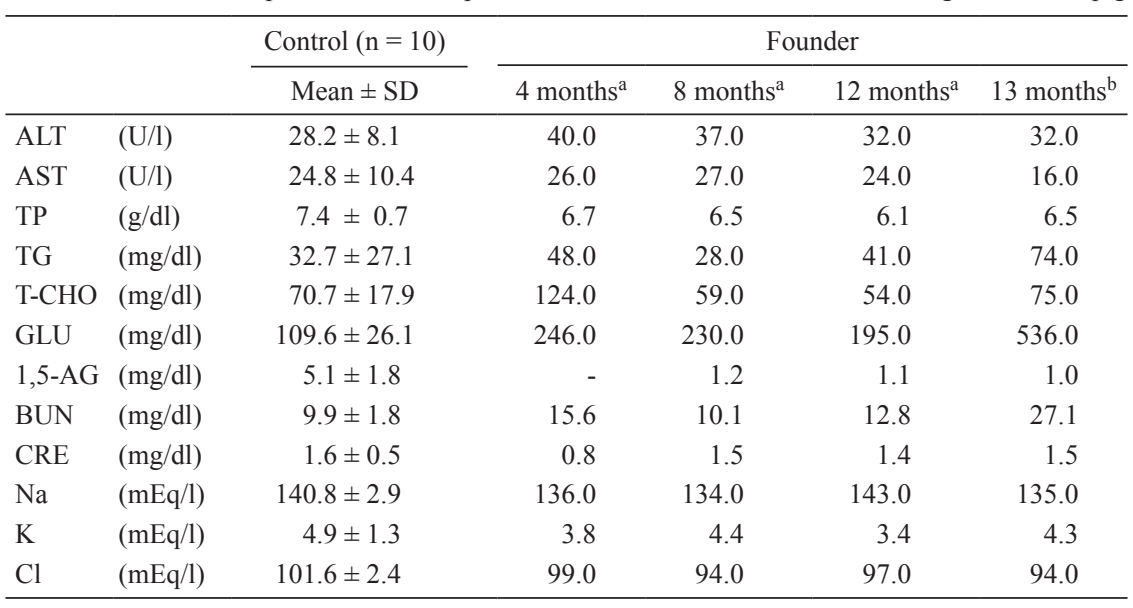

a Treated with insulin. ${ }^{\mathrm{b}}$ Not treated with insulin. 1,5-AG, 1,5-anhydroglucitol; AST, aspirate aminotransferase; ALT, alanine aminotransferase; BUN, blood urea nitrogen; $\mathrm{Cl}$, chloride; CRE, creatinine; GLU, glucose; K, potassium; Na, sodium; T-CHO, total cholesterol; TG, triglyceride; TP, total protein.

pigs (Table 1).

The founder Tg-cloned boar grew steadily and reached a peak weight of $169 \mathrm{~kg}$ at 12 months. The growth rate during the period between 3.5 months and 11 months was $3.7 \mathrm{~kg} /$ week, which was consistent with that of healthy wild-type (WT) pigs (3.6 kg/week). When insulin administration was temporarily stopped at 13 months, the founder pig started to lose weight, non-fasting blood glucose levels reached $536 \mathrm{mg} / \mathrm{dl}$ and BUN and TG levels worsened (Table 1). Therefore, these analyses demonstrated that the founder Tg-cloned boar exhibited typical diabetic symptoms that could be controlled by insulin administration.

Following the successful rearing of this founder Tg-cloned boar, we removed one testis at 8 months and the other at 12 months. Epididymal sperm was collected from each testis and cryopreserved using the method described by Kikuchi et al. [6] with a slight modification. After thawing, sperm samples were used for IVF and intrafallopian insemination.

The fertilization capacities of the Tg-cloned boar sperm at 8 months (DM-8m) and 12 months (DM-12m) of age were compared with those of WT boar sperm via IVF using IVM oocytes. IVF was performed using previously reported methods [7, 8] with slight modifications. A preliminary experiment revealed the optimal insemination concentration was $1.0 \times 10^{6}$ cells $/ \mathrm{ml}$ for IVF with the WT boar sperm. Therefore, we adopted this condition for IVF with the Tg-cloned boar sperm.

The fertilization rate with the Tg-cloned boar sperm was significantly $(\mathrm{P}<0.05)$ lower than that with WT boar sperm: WT, 54.6\%; DM-8m, 26.7\%; DM-12m, 24.0\%. IVF with the DM-8m sperm yielded rates of normal cleavage and blastocyst formation equivalent to IVF with WT sperm (Table 2). However, use of DM-12m sperm for IVF significantly reduced the rate of embryonic development (Table 2).

The blood glucose level of the founder Tg-cloned boar was maintained at slightly higher levels than normal to avoid hypoglycemic coma. The fact that the $\mathrm{Tg}$ boar was maintained under suboptimal conditions for more than 6 months may have had a negative influ- ence on sperm quality. Reduced sperm quality in male diabetic patients has been reported by several groups $[9,10]$. Paasch et al. (2011) [11] reported increased accumulation of eppin (epididymal proteinase inhibitor) protein complex components, such as clusterin, lactotransferrin and semenogelin-1, in the sperm plasma membranes of diabetic patients. They also noted a possible influence of this eppin accumulation on the fertilization capacity of the sperm. A morphological study by Baccetti et al. (2002) [12] of diabetic patients' sperm indicated an increased incidence of acrosomal abnormalities and aberrations of the sperm nuclei and tails. Together, these results suggest that the sperm quality of the Tg-cloned boar was adversely affected by diabetic symptoms.

The fertilization rate of porcine IVF has been reported to increase with sperm concentration $[13,14]$. Thus, we examined whether elevated Tg-cloned boar sperm concentrations, above the level optimal for WT boar sperm $\left(1.0 \times 10^{6}\right)$, could improve the outcome of IVF. We found that embryo cleavage rates and blastocyst formation rates were highest at $2.5 \times 10^{6}$ cells $/ \mathrm{ml}$ and $5 \times 10^{6}$ cells $/ \mathrm{ml}$ for the DM- $8 \mathrm{~m}$ and DM-12m sperm, respectively (Table 3 ). Both of these concentrations are far above the optimal sperm concentration for WT boars in our experimental settings. These results may be coincident with the deteriorated fertility of the DM-12m sperm.

Next, we examined whether live piglets could be produced by IVF using cryopreserved Tg-cloned boar sperm. DM-12m sperm was used for IVF to verify the utility of the reduced-quality cryopreserved sperm. The insemination concentration was set at $5 \times 10^{6}$ cells $/ \mathrm{ml}$, and the resultant embryos at either the 1-8-cell stage (days 1-3) or the blastocyst stage (days 5-6) were transferred to estrus-synchronized recipients. In total, 319 embryos at the 1-8-cell stage were transferred into four recipient gilts; three became pregnant and gave birth to 22 live piglets. Seven of the live piglets $(31.8 \%)$ were transgenic, carrying the human mutant HNF-1 $\alpha$ transgene (Table 4). All of the $\mathrm{Tg}$ piglets exhibited hyperglycemia similar to the founder Tg-cloned boar, except for three of the Tg piglets that died before one week of 
Table 2. Efficiency of fertilization and development of porcine oocytes fertilized in vitro with cryopreserved boar sperm

\begin{tabular}{lcccccccc}
\hline \multirow{2}{*}{$\begin{array}{c}\text { Type of } \\
\text { sperm }\end{array}$} & $\begin{array}{c}\text { Inseminated sperm } \\
\text { concentration } \\
\left(\times 10^{6} \text { cells } / \mathrm{ml}\right)\end{array}$ & $\begin{array}{c}\text { Examined after } \\
\text { insemination }\end{array}$ & $\begin{array}{c}\text { Fertilized } \\
(\%)\end{array}$ & $\begin{array}{c}\text { Normally } \\
\text { fertilized (\%) }\end{array}$ & & $\begin{array}{c}\text { Cultured after } \\
\text { insemination }\end{array}$ & $\begin{array}{c}\text { Normally } \\
\text { cleaved (\%) }\end{array}$ & $\begin{array}{c}\text { Developed to the } \\
\text { blastocyst stage }(\%)\end{array}$ \\
\hline WT & 1.0 & 97 & $53(54.6)^{\mathrm{a}}$ & $25(47.2)^{\mathrm{a}}$ & & 69 & $42(60.9)^{\mathrm{a}}$ & $32(46.4)^{\mathrm{a}}$ \\
DM-8m & 1.0 & 45 & $12(26.7)^{\mathrm{b}}$ & $10(83.3)$ & & 37 & $19(51.4)^{\mathrm{a}}$ & $14(37.8)^{\mathrm{a}}$ \\
DM-12m & 1.0 & 125 & $30(24.0)^{\mathrm{b}}$ & $28(93.3)^{\mathrm{b}}$ & & 83 & $23(27.7)^{\mathrm{b}}$ & $14(16.9)^{\mathrm{b}}$ \\
\hline
\end{tabular}

${ }^{\text {ab }}$ Significant differences $(\mathrm{P}<0.05)$.

Table 3. Determination of optimal sperm concentration for in vitro fertilization of cryopreserved diabetic boar sperm

\begin{tabular}{|c|c|c|c|c|c|c|c|}
\hline \multirow{2}{*}{$\begin{array}{l}\text { Type of } \\
\text { sperm }\end{array}$} & \multirow{2}{*}{$\begin{array}{l}\text { Inseminated sperm } \\
\text { concentration } \\
\left(\times 10^{6} \text { cells } / \mathrm{ml}\right)\end{array}$} & \multicolumn{3}{|c|}{ No. of oocytes } & \multicolumn{3}{|c|}{ No. of oocytes } \\
\hline & & $\begin{array}{l}\text { Examined after } \\
\text { insemination }\end{array}$ & $\begin{array}{c}\text { Fertilized } \\
\quad(\%)\end{array}$ & $\begin{array}{c}\text { Normally } \\
\text { fertilized (\%) }\end{array}$ & $\begin{array}{l}\text { Cultured after } \\
\text { insemination }\end{array}$ & $\begin{array}{l}\text { Normally } \\
\text { cleaved (\%) }\end{array}$ & $\begin{array}{l}\text { Developed to the } \\
\text { blastocyst stage (\%) }\end{array}$ \\
\hline \multirow{3}{*}{ DM-8m } & 1.0 & 45 & $12(26.7)^{\mathrm{a}}$ & $10(83.3)$ & 37 & $19(51.4)$ & $14(37.8)$ \\
\hline & 2.5 & 125 & $86(68.8)^{\mathrm{b}}$ & $45(52.3)$ & 71 & $48(67.6)^{\mathrm{a}}$ & $41(57.7)$ \\
\hline & 5.0 & 129 & $71(55.0)^{\mathrm{b}}$ & $45(63.4)$ & 66 & $31(47.0)^{\mathrm{b}}$ & $30(45.5)$ \\
\hline \multirow{3}{*}{ DM-12m } & 1.0 & 125 & $30(24.0)^{\mathrm{a}}$ & $28(93.3)$ & 83 & $23(27.7)^{a}$ & $14(16.9)^{\mathrm{a}}$ \\
\hline & 2.5 & 144 & $60(41.7)^{\mathrm{b}}$ & $51(85.0)$ & 95 & $43(45.3)^{b}$ & $33(34.7)^{b}$ \\
\hline & 5.0 & 112 & $70(62.5)^{\mathrm{c}}$ & $58(82.9)$ & 67 & $38(56.7)^{\mathrm{b}}$ & $34(50.7)^{\mathrm{b}}$ \\
\hline
\end{tabular}

ab, ac, bc Significant differences $(\mathrm{P}<0.05)$.

Table 4. Production of offspring by in vitro fertilization and intrafallopian insemination of cryopreserved diabetic boar sperm

\begin{tabular}{|c|c|c|c|c|c|c|}
\hline Methods & Recipients & $\begin{array}{l}\text { No. of embryos } \\
\text { transferred }\end{array}$ & $\begin{array}{l}\text { No. of live piglets } \\
\text { ( } \operatorname{tg} \text { piglets included) }\end{array}$ & $\begin{array}{l}\text { No. of stillborn piglets } \\
\text { (tg piglets included) }\end{array}$ & $\begin{array}{l}\text { Proportion of tg } \\
\text { piglets/litter (\%) }\end{array}$ & $\begin{array}{l}\text { Average (mean } \pm \text { SEM) body } \\
\text { weight of piglets at birth }(\mathrm{kg})\end{array}$ \\
\hline \multirow{4}{*}{$\mathrm{IVF} 1^{\mathrm{a}}$} & P57 & 70 & $11(4)$ & $3(0)$ & $4 / 14(28.6)$ & $0.56 \pm 0.05$ \\
\hline & P84 & 112 & $7(2)$ & $0(0)$ & 2/7 (28.6) & $1.09 \pm 0.06$ \\
\hline & P162 & 93 & $4(1)$ & $4(3)$ & $4 / 8(50.0)$ & $0.70 \pm 0.13$ \\
\hline & P58 ${ }^{\mathrm{c}}$ & 44 & - & - & - & - \\
\hline \multirow{2}{*}{ IVF- $2^{\mathrm{b}}$} & P99 & 20 & $4(1)$ & $3(1)$ & $2 / 7(28.6)$ & $0.75 \pm 0.10$ \\
\hline & P135 & 15 & $5(2)$ & $0(0)$ & $2 / 5(40.0)$ & $0.84 \pm 0.09$ \\
\hline \multirow{4}{*}{$\begin{array}{l}\text { Intrafallopian } \\
\text { insemination }\end{array}$} & B47 & $10^{\mathrm{d}}$ & $6(4)$ & $2(2)$ & $6 / 8(75.0)$ & $1.07 \pm 0.05$ \\
\hline & $\mathrm{B} 45^{\mathrm{c}}$ & $10^{\mathrm{d}}$ & - & - & - & - \\
\hline & $\mathrm{B} 46^{\mathrm{c}}$ & $8^{\mathrm{d}}$ & - & - & - & - \\
\hline & $\mathrm{B} 51^{\mathrm{c}}$ & $14^{\mathrm{d}}$ & - & - & - & - \\
\hline
\end{tabular}

\footnotetext{
${ }^{a}$ Embryos were transferred at the 1-8-cell stage. ${ }^{b}$ Embryos were transferred at the blastocyst stage. ${ }^{\mathrm{c}}$ Returned to estrus. ${ }^{\mathrm{d}}$ No. of ovulations.
}

age. Four of the Tg piglets developed to the weaning stage.

A total of 35 blastocysts produced by IVF were transferred into two recipients, both of which became pregnant. The gilts produced 9 live piglets, of which three (33.3\%) were transgenic (Table 4$)$. One of those developed to the weaning stage and exhibited hyperglycemia.

These results demonstrated that DM-12m sperm could be used to produce viable piglets through IVF despite reduced fertility.

Piglets were also produced by intrafallopian insemination using cryopreserved Tg-cloned boar sperm. DM-8m sperm, which exhibited better fertilization capacity in IVF, was used to minimize the risk of infertility in this in vivo experiment. Insemination of four ovulationinduced gilts resulted in one pregnancy, which produced four live (66.7\%) Tg piglets out of six farrowed (Table 4). Three of the four Tg piglets developed to the weaning stage and exhibited hyperglycemia.
In this study, we demonstrated that IVF and intrafallopian insemination using cryopreserved epididymal sperm were effective in reproducing the diabetes model Tg pig. Production of offspring through artificial reproductive technology was possible even using reduced-quality sperm from the founder Tg boar; therefore, this approach should be applicable for other pig strains that model human diseases.

\section{Materials and Methods}

\section{Animal care}

The Institutional Animal Care and Use Committee of Meiji University approved all animal experiments in this study (IACUC 09-0006). 
In vitro maturation of porcine oocytes

SCNT and IVF were performed using IVM oocytes. Porcine ovaries were collected at a local abattoir and transported to the laboratory in Dulbecco's phosphate-buffered saline (DPBS; Nissui Pharmaceutical, Tokyo, Japan) containing $75 \mu \mathrm{g} / \mathrm{ml}$ potassium penicillin G, $50 \mu \mathrm{g} /$ $\mathrm{ml}$ streptomycin sulfate, $2.5 \mu \mathrm{g} / \mathrm{ml}$ amphotericin B and $0.1 \%(\mathrm{w} / \mathrm{v})$ polyvinyl alcohol (PVA). Cumulus-oocyte complexes (COCs) were collected by aspiration from ovarian antral follicles with a diameter of $3.0-6.0 \mathrm{~mm}$. COCs with at least three layers of compacted cumulus cells were selected and cultured in NCSU23 medium [15] supplemented with $0.6 \mathrm{mM}$ cysteine, $10 \mathrm{ng} / \mathrm{ml}$ epidermal growth factor (EGF), $10 \%$ (v/v) porcine follicular fluid, $75 \mu \mathrm{g} / \mathrm{ml}$ potassium penicillin $\mathrm{G}, 50$ $\mu \mathrm{g} / \mathrm{ml}$ streptomycin sulfate, $10 \mathrm{IU} / \mathrm{ml}$ equine chorionic gonadotropin (eCG; ASKA Pharmaceutical, Tokyo, Japan) and $10 \mathrm{IU} / \mathrm{ml}$ human chorionic gonadotropin (hCG; ASKA Pharmaceutical). The COCs were cultured for $22 \mathrm{~h}$ with hormones in a humidified atmosphere of $5 \% \mathrm{CO}_{2}$ and $95 \%$ air at $38.5 \mathrm{C}$, followed by additional culture for $18-20 \mathrm{~h}$ without hormones in a humidified atmosphere of $5 \%$ $\mathrm{CO}_{2}, 5 \% \mathrm{O}_{2}$ and $90 \% \mathrm{~N}_{2}$ at $38.5 \mathrm{C}$.

\section{Production of Tg embryos by somatic cell cloning}

Porcine fetal fibroblast cells (\#111-4) carrying an expression vector for the mutant human HNF-1 $\alpha$ cDNA (HNF-1 $\alpha$ P291fsinsC), which had been established in our previous study [4], were used as nuclear donor cells. SCNT was performed using IVM oocytes as recipient cytoplasts as described elsewhere [5]. SCNT embryos were cultured in porcine zygote medium-5 (PZM-5; Research Institute for the Functional Peptides, Yamagata, Japan) in a humidified atmosphere of $5 \% \mathrm{CO}_{2}, 5 \% \mathrm{O}_{2}$ and $90 \% \mathrm{~N}_{2}$ at $38.5 \mathrm{C}$ for 1 or 2 days, and then they were transferred into an estrus-synchronized recipient.

\section{Cryopreservation of boar spermatozoa from epididymides}

The cauda epididymides of the founder Tg-cloned boar and a WT boar (17 months old) were removed under general anesthesia and transferred to the laboratory at ambient temperature. Luminal fluid containing spermatozoa was extruded from the distal portion of each cauda epididymis by air pressure from a syringe, followed by perfusion with approximately $10 \mathrm{ml}$ of collecting solution [6]. The recovered sperm suspension was diluted to a concentration of $2.0 \times 10^{9}$ cells/ $\mathrm{ml}$ by adding collecting solution. The sperm suspension was then cooled down from $25 \mathrm{C}$ to $15 \mathrm{C}$ over $60 \mathrm{~min}$ (average cooling rate: $0.17 \mathrm{C} / \mathrm{min}$ ). After incubation for $2 \mathrm{~h}$ at $15 \mathrm{C}$, the sperm suspension was centrifuged at $800 \times g$ for $10 \mathrm{~min}$ at $15 \mathrm{C}$ and the supernatant was discarded. Precipitated spermatozoa were resuspended in equal amounts of Niwa and Sasaki Freezing (NSF)-I extender [6]. The sperm suspension was again cooled down from $15 \mathrm{C}$ to $5 \mathrm{C}$ over $120 \mathrm{~min}$ (average cooling rate: $0.08 \mathrm{C} / \mathrm{min}$ ) and was then diluted to a concentration of $2.0 \times 10^{9} \mathrm{cells} / \mathrm{ml}$ with NSF-I extender. It was finally mixed with an equal volume of NSF-II extender containing $6 \%(\mathrm{v} / \mathrm{v})$ glycerol [6]. The sperm suspension $(0.2-0.3 \mathrm{ml})$ was loaded in 0.5-ml plastic straws (Cryo Bio System, Paris, France). The straws were the placed in liquid nitrogen vapor $(-150 \mathrm{C})$ approximately 4 $\mathrm{cm}$ above the surface of liquid nitrogen for $20 \mathrm{~min}$ and were finally plunged into liquid nitrogen.
IVF

IVF was performed using IVM oocytes with expanded cumulus cells [16]. A straw containing frozen sperm was thawed by immersion in warm water (37 C) for 30 seconds. The sperm were then suspended in $5 \mathrm{ml}$ DPBS supplemented with $0.1 \%$ bovine serum albumin (Wako Pure Chemical Industries, Osaka, Japan) and washed three times by centrifugation at $1,000 \times g$ for $4 \mathrm{~min}$. After washing, the sperm pellets were resuspended in porcine fertilization medium (PFM; Research Institute for the Functional Peptides) at a concentration of $1 \times 10^{7}$ cells $/ \mathrm{ml}$.

For insemination, $20 \mathrm{COCs}$ that had been matured in vitro were placed in a 100- $\mu$ ldrop of PFM containing spermatozoa $\left(1.0-5.0 \times 10^{6}\right.$ cells $/ \mathrm{ml}$ ); the oocytes and sperm were incubated for $8 \mathrm{~h}$ at $38.5 \mathrm{C}$ in a humidified atmosphere containing $5 \% \mathrm{CO}_{2}, 5 \% \mathrm{O}_{2}$ and $90 \% \mathrm{~N}_{2}$. After insemination, the eggs were transferred to Tyrode lactose medium containing $10 \mathrm{mM}$ Hepes and $0.3 \%(\mathrm{w} / \mathrm{v})$ polyvinylpyrrolidone (Hepes-TL-PVP); cumulus cells and excess sperm were removed by gentle pipetting. Eggs that showed release of one or more polar bodies with normal cytoplasmic morphology were cultured (20-30 eggs/20-30 $\mu 1$ drop) in PZM-5 under paraffin oil (Kanto Chemical, Tokyo, Japan) in a plastic petri dish maintained in an atmosphere of $5 \% \mathrm{CO}_{2}, 5 \% \mathrm{O}_{2}$ and $90 \% \mathrm{~N}_{2}$ at $38.5 \mathrm{C}$ until transfer. Eggs were cultured beyond the morula stage by adding $10 \%(\mathrm{v} / \mathrm{v})$ fetal calf serum to the medium.

Some eggs were fixed in 1:3 acetic acid:methanol after $12 \mathrm{~h}$ of culture and then stained with $1 \%$ aceto-orcein. Eggs with two pronuclei and two polar bodies were considered to have undergone normal fertilization. Other categories of fertilized eggs were identified as polyspermic: eggs with two pronuclei, two polar bodies and a swollen sperm head(s) and eggs with three or more pronuclei.

\section{Embryo transfer}

Crossbred (Large White / Landrace X Duroc) prepubertal gilts weighing $100-105 \mathrm{~kg}$ were used as recipients. To induce estrus in the gilts, $1000 \mathrm{IU}$ of eCG was injected intramuscularly, followed by an injection of $1500 \mathrm{IU}$ hCG (Kyoritsu Seiyaku Corporation, Tokyo, Japan) $66 \mathrm{~h}$ later.

SCNT embryos were transferred at the 1-cell (day 1) or 2-8-cell (day 2) stages into the oviducts of estrus-synchronized recipient gilts by midventral laparotomy under general anesthesia [5]. Transfer of in vitro-fertilized embryos was conducted at 1-8-cell (days 1-3) or blastocyst (days 5-6) stage. Embryos on days 1-2, day 3 and days 5-6 were respectively transferred to recipients at $51-54 \mathrm{~h}, 75-78$ $\mathrm{h}$ and $147-150 \mathrm{~h}$ after the $\mathrm{hCG}$ injection. Pregnant recipients were allowed to farrow, and piglets obtained were raised with the standard diet and water ad libitum.

\section{Intrafallopian insemination}

The gilts used for the intrafallopian insemination experiment were induced to ovulate by an injection of $1000 \mathrm{IU}$ eCG, followed $72 \mathrm{~h}$ later by administration of $1500 \mathrm{IU}$ hCG. Intrafallopian insemination was performed by midventral laparotomy approximately $46 \mathrm{~h}$ after $\mathrm{hCG}$ injection. The ovaries of estrus-induced recipients were examined to confirm that ovulation had occurred. Frozen-thawed epididymal sperm suspended in Beltsville thawing solution [17] at a concentration of $2.7 \times 10^{7}$ cells $/ 0.1 \mathrm{ml}$ were injected into both ampullae of the fallopian 
tubes using a 3.5 Fr catheter (Tom Cat Catheter, Tyco Healthcare Group, Mansfield, MA, USA) with a syringe. The proportion of sperm with progressive motility was $30 \%$.

\section{Control of blood glucose levels in the diabetic founder boar}

Blood glucose levels were measured daily (morning and evening) with a glucose test meter (GLUCOCARD GT-1820, Arkray, Kyoto, Japan) using blood samples from the ear vein. The diabetic founder pig received a subcutaneous injection of insulin glargine (0.5-1.1 $\mathrm{U} / \mathrm{kg}$ ) at the time of feeding in the morning. Blood glucose levels were measured again 60-90 min after feeding, and a subcutaneous injection of regular insulin $(0-0.2 \mathrm{U} / \mathrm{kg})$ was given to maintain a blood glucose level of approximately $200 \mathrm{mg} / \mathrm{dl}$.

\section{Biochemical analysis of blood components}

Venous blood samples were collected in tubes containing heparin to determine the concentrations of aspirate aminotransferase (AST), alanine aminotransferase (ALT), blood urea nitrogen (BUN), creatinine (CRE), glucose (GLU), total cholesterol (T-CHO), triglyceride (TG), total protein $(\mathrm{TP})$, sodium $(\mathrm{Na})$, potassium $(\mathrm{K})$ and chloride $(\mathrm{Cl})$ using a dry-chemistry analyzer (FUJI DRI-CHEM 7000, FUJIFILM Corporation, Tokyo, Japan). The concentration of 1,5-anhydroglucitol (1,5-AG) was determined using the enzymatic method (SRL, Tokyo, Japan).

\section{Determination of transgenic offspring}

Determination of transgenic offspring was performed using PCR. Genomic DNA was extracted from offspring tail tissue, purified with a DNeasy Blood \& Tissue Kit (QIAGEN, Tokyo, Japan) and amplified using TaKaRa Ex Taq (Takara Bio, Shiga, Japan) with the following set of primers: 5'-AGGACCTGAGCCTGCCGAGCAAC-3' and 5'-AGGGCTCTCCATAGGCCCAGGCT-3'. The PCR conditions were as follows: $94 \mathrm{C}$ for $3 \mathrm{~min}$, followed by 25 cycles of $94 \mathrm{C}$ for $30 \mathrm{~s}, 60 \mathrm{C}$ for $15 \mathrm{~s}$ and $72 \mathrm{C}$ for $20 \mathrm{~s}$.

\section{Statistics}

Statistical analyses were performed using the SPSS 16.0 software (SPSS, Chicago, IL, USA). Differences in the rates of fertilization and embryo development between the DM sperm and control WT sperm were analyzed using a $\chi^{2}$ test.

\section{Acknowledgments}

This work was supported by a Grant-in-Aid for Scientific Re- search (C) (\#23500505) from the Ministry of Education, Culture, Sports, Science and Technology/Japan Society for the Promotion of Science and by the Program for Promotion of Basic Research Activities for Innovative Bioscience (PROBRAIN), Tokyo, Japan.

\section{References}

1. Lunney JK. Advances in swine biomedical model genomics. Int J Biol Sci 2007; 3: 179-184. [Medline]

2. Whyte JJ, Prather RS. Genetic modifications of pigs for medicine and agriculture. $\mathrm{Mol}$ Reprod Dev 2011; 78: 879-891. [Medline]

3. Luo Y, Lin L, Bolund L, Jensen TG, Sorensen CB. Genetically modified pigs for biomedical research. J Inherit Metab Dis 2012; 35: 695-713. [Medline]

4. Umeyama K, Watanabe M, Saito H, Kurome M, Tohi S, Matsunari H, Miki K, Nagashima H. Dominant-negative mutant hepatocyte nuclear factor 1alpha induces diabetes in transgenic-cloned pigs. Transgenic Res 2009; 18: 697-706. [Medline]

5. Matsunari H, Onodera M, Tada N, Mochizuki H, Karasawa S, Haruyama E, Nakayama N, Saito H, Ueno S, Kurome M, Miyawaki A, Nagashima H. Transgeniccloned pigs systemically expressing red fluorescent protein, Kusabira-Orange. Cloning Stem Cells 2008; 10: 313-323. [Medline]

6. Kikuchi K, Nagai T, Kashiwazaki N, Ikeda H, Noguchi J, Shimada A, Soloy E, Kaneko H. Cryopreservation and ensuing in vitro fertilization ability of boar spermatozoa from epididymides stored at 4 degrees C. Theriogenology 1998; 50: 615-623. [Medline]

7. Funahashi H, Nagai T. Regulation of in vitro penetration of frozen-thawed boar spermatozoa by caffeine and adenosine. Mol Reprod Dev 2001; 58: 424-431. [Medline]

8. Yoshioka K, Suzuki C, Itoh S, Kikuchi K, Iwamura S, Rodriguez-Martinez H. Production of piglets derived from in vitro-produced blastocysts fertilized and cultured in chemically defined media: effects of theophylline, adenosine, and cysteine during in vitro fertilization. Biol Reprod 2003; 69: 2092-2099. [Medline]

9. Vignon F, Le Faou A, Montagnon D, Pradignac A, Cranz C, Winiszewsky P, Pinget M. Comparative study of semen in diabetic and healthy men. Diabete Metab 1991; 17 350-354. [Medline]

10. Handelsman DJ, Conway AJ, Boylan LM, Yue DK, Turtle JR. Testicular function and glycemic control in diabetic men. A controlled study. Andrologia 1985; 17: 488-496. [Medline]

11. Paasch U, Heidenreich F, Pursche T, Kuhlisch E, Kettner K, Grunewald S, Kratzsch J, Dittmar G, Glander HJ, Hoflack B, Kriegel TM. Identification of increased amounts of eppin protein complex components in sperm cells of diabetic and obese individuals by difference gel electrophoresis. Mol Cell Proteomics 2011; 10: M110.007187. [Medline]

12. Baccetti B, La Marca A, Piomboni P, Capitani S, Bruni E, Petraglia F, De Leo V. Insulin-dependent diabetes in men is associated with hypothalamo-pituitary derangement and with impairment in semen quality. Hum Reprod 2002; 17: 2673-2677. [Medline]

13. Wang WH, Niwa K, Okuda K. In-vitro penetration of pig oocytes matured in culture by frozen-thawed ejaculated spermatozoa. J Reprod Fertil 1991; 93: 491-496. [Medline]

14. Yi YJ, Park CS. Effects of sperm concentrations and culture media on fertilization and development of in vitro matured pig oocytes. Zygote 2004; 12: 263-267. [Medline]

15. Petters RM, Wells KD. Culture of pig embryos. J Reprod Fertil Suppl 1993; 48: 61-73. [Medline]

16. Maehara M, Matsunari H, Honda K, Nakano K, Takeuchi Y, Kanai T, Matsuda T, Matsumura Y, Hagiwara Y, Sasayama N, Shirasu A, Takahashi M, Watanabe M, Umeyama K, Hanazono Y, Nagashima H. Hollow fiber vitrification provides a novel method for cryopreserving in vitro maturation/fertilization-derived porcine embryos. Biol Reprod 2012; 87: 133-140. [Medline]

17. Pursel VG, Johnson LA. Freezing of boar spermatozoa: fertilizing capacity with concentrated semen and a new thawing procedure. J Anim Sci 1975; 40: 99-102. [Medline] 